\title{
¿Un socialismo barroco?
}

\author{
BOLÍVAR ECHEVERRÍA \\ Facultad de Filosofía y Letras \\ Universidad Nacional Autónoma de México \\ bolivare@servidor.unam.mx
}

\begin{abstract}
Resumen: El cuádruple ethos histórico de la modernidad es una estrategia de supervivencia del ser humano para sobreponerse a la enajenación capitalista y neutralizar la contradicción fundamental entre valor de uso y valor en el mundo de la vida. Junto a él están el ethos realista, el ethos romántico y el ethos clásico. El ethos barroco no es la característica de ninguna identidad social sustancial. No corresponde a la identidad de América Latina, sino que esta identidad recurre con preferencia al ethos barroco. Una posible modernidad socialista en la América Latina tendría las huellas de la modernidad capitalista de tendencia barroca a la que vendría a sustituir.
\end{abstract}

Palabras clave: ethos barroco, capitalismo, enajenación, América Latina

\begin{abstract}
The historical ethos of Modernity is a survival strategy developed by human beings in order to overcome capitalist alienation and to neutralize the fundamental contradiction between value in use and economic value in the "world of life". Along with it, there are three other modern ethe: the realistic, the romantic and the classic one. The baroque ethos is not a feature of any substantial social identity. It does not belong to the identity of Latin America, but rather this identity preferably appeals to the baroque ethos. A possible socialist modernity in Latin America will probably bear the traces of the baroque capitalist modernity replaced by it.

Key words: baroque ethos, capitalism, alienation, Latin America
\end{abstract}

Los usos y costumbres del mundo intelectual y académico latinoamericano consideran de mal gusto reconocer en el coterráneo la capacidad de generar ideas propias, dignas de ser tenidas en cuenta críticamente, sea para desecharlas o para adoptarlas; desde el siglo XVIII, entre nosotros las ideas de buena calidad sólo pueden ser artículos de importación. Por ello me extraña con halago que Samuel Arriarán opine que mi concepto de ethos barroco merece la pena de ser discutido. Por lo demás, le agradezco que, tras examinarlo, haya llegado a la conclusión de que "no todo en él es negativo".

La lectura que Arriarán hace de mis textos está guiada por una preocupación - muy compartible - acerca de la medida en que una teoría como la del ethos barroco puede enriquecer el análisis sobre las posibilidades actuales de una transformación revolucionaria en la sociedad latinoamericana. Con miras a un posible intercambio de opiniones en el futuro, quisiera por lo pronto presentar solamente las siguientes puntualizaciones.

1. El concepto de ethos barroco hace referencia a una de las cuatro posibilidades que tiene el ser humano en la modernidad capitalista -la única "realmente existente" - de elaborar una estrategia cotidiana de sobrevivencia que le permita soportar la enajenación, es decir, neutralizar la 
contradicción inherente al modo capitalista de la reproducción social. El ethos realista y el ethos romántico se basan en una disposición profunda a borrar o denegar la divergencia esencial entre el principio que rige la reproducción social en su "forma natural", como productora/consumidora de objetos concretos o con valor de uso, y el principio que impera en esta reproducción en cuanto productora/consumidora del valor capitalista o valor que se autovaloriza. Por el contrario, el ethos barroco, junto con el ethos neoclásico, se basa en una tendencia estructural a resaltar y advertir esa divergencia esencial. El ethos barroco sólo se distingue del neoclásico en que, a diferencia de éste, no se aviene con el sacrificio de la "forma natural" de las cosas o de su valor de uso en aras del valor económico capitalista, sino que se aferra a él y lo revive en el plano de lo imaginario. De este modo, el concepto de ethos barroco se refiere a una versión del ethos histórico moderno que, combinada con las otras tres, y subordinante o subordinada respecto de ellas, puede encontrarse en cualquier situación concreta de la vida moderna capitalista.

2. En principio, el ethos barroco, como forma o modo de comportamiento, no pertenece a la sustancia de ninguna identidad social históricamente identificada, ni puede ser una emanación de ella. Pero sí es posible que determinadas sociedades, como las de ciertas regiones clave de América Latina, debido a circunstancias económicas y sociales recurrentes lo incluyan a través de su historia como elemento característico de su identificación concreta. La predilección por la estrategia barroca en la adopción del capitalismo apareció en América Latina en el siglo XVII a causa de la debilidad que demostró la forma capitalista de la vida social al imponerse y sustituir las "formas naturales" premodernas. La "lógica del valor de uso", vigente desde la transfiguración imaginaria de éste, demostró ser más potente que la "lógica del valor" en la configuración de la vida cotidiana. En las sociedades americanas históricamente decisivas de esa época, la predilección por el barroquismo provino del empleo que los restos urbanizados de la población indígena hacían de la estrategia barroca: para salvar el mundo americano de la barbarie, que parecía ser el epílogo ineluctable de la Conquista, reconstruían en la práctica, con los cabos sueltos del mismo y con la ayuda de los "hijastros" de España, una imitación o representación escénica de la civilización europea, un mundo inventado donde en muchos sentidos los latinoamericanos de hoy nos encontramos todavía.

3. El "cuádruple ethos de la modernidad capitalista", y el ethos barroco dentro de él, incluye distintas estrategias desarrolladas para vivir dentro de esa modernidad, ya sea animosamente (como el realista o el romántico), ya sea a regañadientes (como el propio barroco y el neoclásico). Una posición de izquierda, revolucionaria, contraria a la modernidad capitalista, que busque sustituir ésta por otra diferente (anarquista, socialista, comunista), 
no puede adoptar ninguna de esas estrategias, puesto que lo que pretende es precisamente pasar a otra configuración de la vida social, en la que no sea necesario partir de lo ineluctable del modo capitalista de reproducir la vida humana y su riqueza.

4. La ventaja que podría tener la perspectiva barroca en comparación con las otras en un proceso social y político de superación de la modernidad capitalista tendría que ver con aquello que mencionaba Hegel acerca de que "toda negación es una negación determinada por aquello que niega". La negación de un capitalismo vivido en la perspectiva barroca debería ser, sin duda, una negación barroca. Gran parte del fracaso, tanto del socialismo revolucionario de inspiración "romántica", como del socialismo reformista de inspiración "neoclásica" en el siglo xx parece haber resultado de la ceguera de estos socialismos ante la exigencia social de una emancipación de la vida que gira en torno a la "forma natural" del mundo de la vida y sus "valores de uso". Tal vez una práctica política "socialista" como la que quisiera promover Samuel Arriarán, que se genere en sociedades identificadas por su preferencia por el ethos barroco y su fidelidad al lado natural, concreto o de valor de uso de la vida humana y sus mundos, pueda ser en efecto la que esté llamada a vencer allí donde las demás sucumbieron.

Recibido el 11 de octubre de 2004; aceptado el 26 de octubre de 2004. 